\title{
Practical considerations of nebulized corticosteroid in children with acute asthmatic exacerbation: A consensus
}

\author{
Chalerat Direkwattanachai, ${ }^{1}$ Chalermthai Aksilp, ${ }^{2}$ Pantipa Chatchatee, ${ }^{3}$ Orathai Jirapongsananuruk,${ }^{4}$ Haruthai Kamalaporn, ${ }^{1}$ \\ Wasu Kamchaisatian, ${ }^{1}$ Sorasak Lochindarat, ${ }^{2}$ Lina Ngamtrakulpanit, ${ }^{5}$ Orapan Poachanukoon, ${ }^{6}$ Muthita Trakultivakorn, ${ }^{7}$ \\ Jamaree Teeratakulpisarn, ${ }^{8}$ Kanokporn Udomittipong, ${ }^{4}$ Mukda Vangveeravong, ${ }^{2}$ Jitladda Deerojanawong ${ }^{3}$
}

\begin{abstract}
Background: Acute asthmatic exacerbation in children causes economic burdens both directly and indirectly. The GINA guideline does mention the use of inhaled or oral corticosteroids in the treatment of asthmatic exacerbation, it provides little practical guidance on the use of nebulized corticosteroid.

Objective: To review and recommend the practical considerations in the use of nebulized corticosteroid in children with acute asthmatic exacerbation.

Methods: This consensus was developed by a group of expert pediatricians in respiratory and allergy fields in Thailand. The recommendations were made based on a review of published studies and clinical opinions. The eligible studies were confined to those published in English, and randomized controlled trials and meta-analyses involving nebulized corticosteroids in asthmatic exacerbation in children aged between 1-18 years.
\end{abstract}

Results: There were 13 randomized controlled-trial studies published from 1998 to 2017. Nine of the 13 studies compared nebulized with systemic corticosteroid conducted in moderate to severe exacerbation, while the remaining four compared nebulized corticosteroid with placebo conducted in mild to severe exacerbation. The admission rate was significantly lower in severe exacerbation (one study) and pooled four mild to severe exacerbation studies comparing with placebo $(p$ 0.022). Other clinical parameters were significantly improved with nebulized corticosteroid such as clinical scores, systemic corticosteroid/bronchodilator use, or shorter ER stays. Only one study used fluticasone, while the other 12 studies conducted by budesonide (92.31\%).

Conclusion: Nebulized corticosteroid may offer an effective therapeutic option for the management of acute exacerbation of asthma in all severities. Nebulized budesonide is the preferred corticosteroid.

Key words: budesonide, admission, bronchodilator, randomized-controlled trial, meta-analysis

\section{Affiliations:}

Department of Pediatrics, Faculty of Medicine,

Ramathibodi Hospital, Mahidol University, Bangkok, Thailand

Department of Medical Services, Queen Sirikit National Institute of

Child Health, Ministry of Public Health, Bangkok, Thailand

Pediatric Allergy \& Clinical Immunology Research Unit, Division

of Allergy and Immunology, Department of Pediatrics, Faculty of

Medicine, Chulalongkorn University, King Chulalongkorn Memorial

Hospital, the Thai Red Cross Society, Bangkok, Thailand

${ }^{4}$ Department of Pediatrics, Faculty of Medicine, Siriraj Hospital,

Mahidol University, Bangkok, Thailand

Bangkok Allergy and Asthma Center Bangkok Hospital, Bangkok, Thailand

${ }^{6}$ Department of Pediatrics, Thammasat University Hospital, Pathum Thani, Thailand

Department of Pediatrics, Faculty of Medicine, Chiang Mai University, Chiang Mai, Thailand

${ }^{8}$ Department of Pediatrics, Faculty of Medicine, Khon Kaen University, Khon Kean, Thailand

\section{Corresponding author:}

Jitladda Deerojanawong

Department of Pediatrics, Faculty of Medicine,

Chulalongkorn University, Bangkok, Thailand

E-mail: jitladda.d@gmail.com

\section{Introduction}

The prevalence of asthma in Thai children was $7.8-15 \%$ and $8.7-13.9 \%$ in 6 - and 13 -year-old children, respectively. ${ }^{1,2}$ A study conducted on 6-12 year-old Thai students with asthma showed that $46.7 \%$ of them were controlled, $43.4 \%$ were partially controlled and $10 \%$ were uncontrolled. ${ }^{3}$ Acute asthmatic exacerbation is still a problem in Thailand. A survey conducted in 400 Thai patients with asthma; $9.5 \%$ had aged between 12 and 17 years showed that 36\% had exacerbations 
in the previous year, 17\% had been hospitalized and 35\% had an unscheduled emergency visit to a healthcare facility. ${ }^{4} \mathrm{~A}$ study on the annual cost of treatment children with asthma in Chiang Mai and Lumphun showed that the average total cost per person was 258 USD, of which 216 USD was direct and 41 USD was indirect. ${ }^{5}$ Similar finding from a study in Ramathibodi Hospital showed that the annual direct costs for asthmatic children aged less than 20-year-old in Thailand was estimated to be 278 USD, of which those patients with at least one exacerbation and without any exacerbation costing 463.6 USD and 241.6 USD respectively. ${ }^{6}$

The 2018 update of the Global Strategy for Asthma Management and Prevention recommends systemic or high-dose inhaled corticosteroid for asthma exacerbation. ${ }^{7}$ Inhaled corticosteroid can be delivered via a pressurized metered-dose inhaler [pMDI], with or without a spacer, a dry powder inhaler [DPI], or a nebulizer. Any types of inhaled corticosteroid should be administered within one hour of presentation to the hospital. Although pMDI with a spacer is commonly used to deliver corticosteroid in children with asthma, nebulized corticosteroid offers an effective option for patients who may be unwilling or unable to use a pMDI. ${ }^{8}$ This is especially relevant in children with an acute asthmatic exacerbation who may be challenged to perform the precision technique with an inhaler.

While the GINA guideline does mention the use of inhaled or oral corticosteroids in the treatment of asthmatic exacerbation, it provides little practical guidance on the use of nebulized corticosteroid. This consensus aims to review and recommend the practical considerations in the use of nebulized corticosteroid in children with acute asthmatic exacerbation.

\section{Methods}

This consensus was developed by a group of expert pediatricians in respiratory and allergy fields in Thailand. A series of meetings was held in Bangkok to discuss the role of nebulized corticosteroid in acute asthmatic exacerbation in children. The recommendations were made based on a review of published studies and clinical opinions. The eligible studies were confined to those published in English, and randomized controlled trials and meta-analyses involving nebulized corticosteroids in asthmatic exacerbation in children aged between $1-18$ years.

\section{Recommendations}

An overview of the treatment algorithm is captured in figure 1. It is adapted from the Thai asthma guideline. ${ }^{9}$

\section{Severity of Asthmatic Exacerbations}

- Nebulized high-dose corticosteroid is recommended in the treatment of all severities [mild, moderate and severe] of asthmatic exacerbation in children at least 1 year old [Figure 1] by the below evidence.

- The severity of asthmatic exacerbation should first be established based on the existence of retraction, degree of difficulty in speaking, $\mathrm{SpO}_{2}$, pulse rate and peak expiratory flow rate, as stipulated in the Thai Asthma guideline. ${ }^{9}$
There were 13 randomized controlled-trial studies published from 1998 to $2017 . .^{10-22}$ Of those, two studies conducted in hospital setting, while the other 10 studies conducted at the emergency room [ER] and one study conducted at an asthma clinic. Nine of the 13 studies compared nebulized with systemic corticosteroid [Table 1] ${ }^{10-18}$ while the remaining four compared nebulized corticosteroid with placebo [Table 2].$^{19-22}$

Studies on moderate to severe asthma exacerbation. Of the nine systemic corticosteroid-controlled studies compared with nebulized budesonide, ${ }^{10-18}$ five studies evaluated the admission rate as the main outcome. There were 200 patients with moderate asthma attack in all studies with age ranged between 1-18 years. All the studies used nebulized budesonide mostly 3 times daily with total dose between 800 microgram and $3 \mathrm{mg}$. Nebulized budesonide had better clinical outcomes over systemic corticosteroid without suppression of pituitary adrenal axis. ${ }^{17}$ Combination of admission rate by the three studies, the admission rate was slightly lower but not different between nebulized budesonide [149/660 patients; $22.58 \%$ ] versus systemic corticosteroid [171/649 patients or $26.35 \%$; p 0.123]..$^{10,11,14}$ In one study from Saudi Arabia 30.9\% of the patients in the study had severe asthma exacerbation. ${ }^{15}$ Treatment with nebulized budesonide vs placebo was compared. The results showed a significant improvement in group with nebulized budesonide in several parameters including clinical scores, ${ }^{11,13,18}$ peak flow, ${ }^{12,15}$ fewer use of bronchodilator, ${ }^{17}$ the reduction in intravenous corticosteroid use, ${ }^{11}$ and shorter length of emergency room stays. ${ }^{15}$ The admission rate in severe case with baseline clinical score of over or equal to 13 was significantly lower in nebulized budesonide group than placebo group $[p 0.03] .{ }^{15}$ There were two studies comparing groups receiving nebulized budesonide versus systemic corticosteroids which showed a better asthma score and a lower use of bronchodilator in the nebulized budesonide group. ${ }^{16,17}$

Studies on mild to severe asthma exacerbation. In the four placebo-controlled studies, which was done in the hospital setting, there were 384 patients with mild to severe asthmatic exacerbation with age ranging from 2 to 15 years. ${ }^{19-22}$ Three studies used nebulized budesonide with daily dose range between 2-11 mg, while another study used $1.5 \mathrm{mg}$ of fluticasone. Two studies from Mexico and China found positive results using nebulized corticosteroids over placebo in clinical score, admission rate, systemic corticosteroid need, and complete remission rate. Even though clinical outcomes in Milani and Sekerel studies were not statistical significant, ${ }^{19,20}$ analysis as a meta-analysis by Chen et al, showed statistical significance. ${ }^{22}$ The admission rate, ${ }^{19,22}$ and systemic corticosteroid need were both statistically different between the nebulized budesonide and placebo arms..$^{20,22}$ The admission rate was significantly higher in placebo $[11 / 69 ; 15.9 \%]$ than nebulized budesonide group $[3 / 76 ; 3.9 \%, p$ 0.022]. Systemic corticosteroid need, an indicator of treatment failure, was also significantly higher in placebo group $[32 / 88 ; 36.4 \%]$ than nebulized budesonide group [12/92; 13.0\%, $p<0.001]$. 


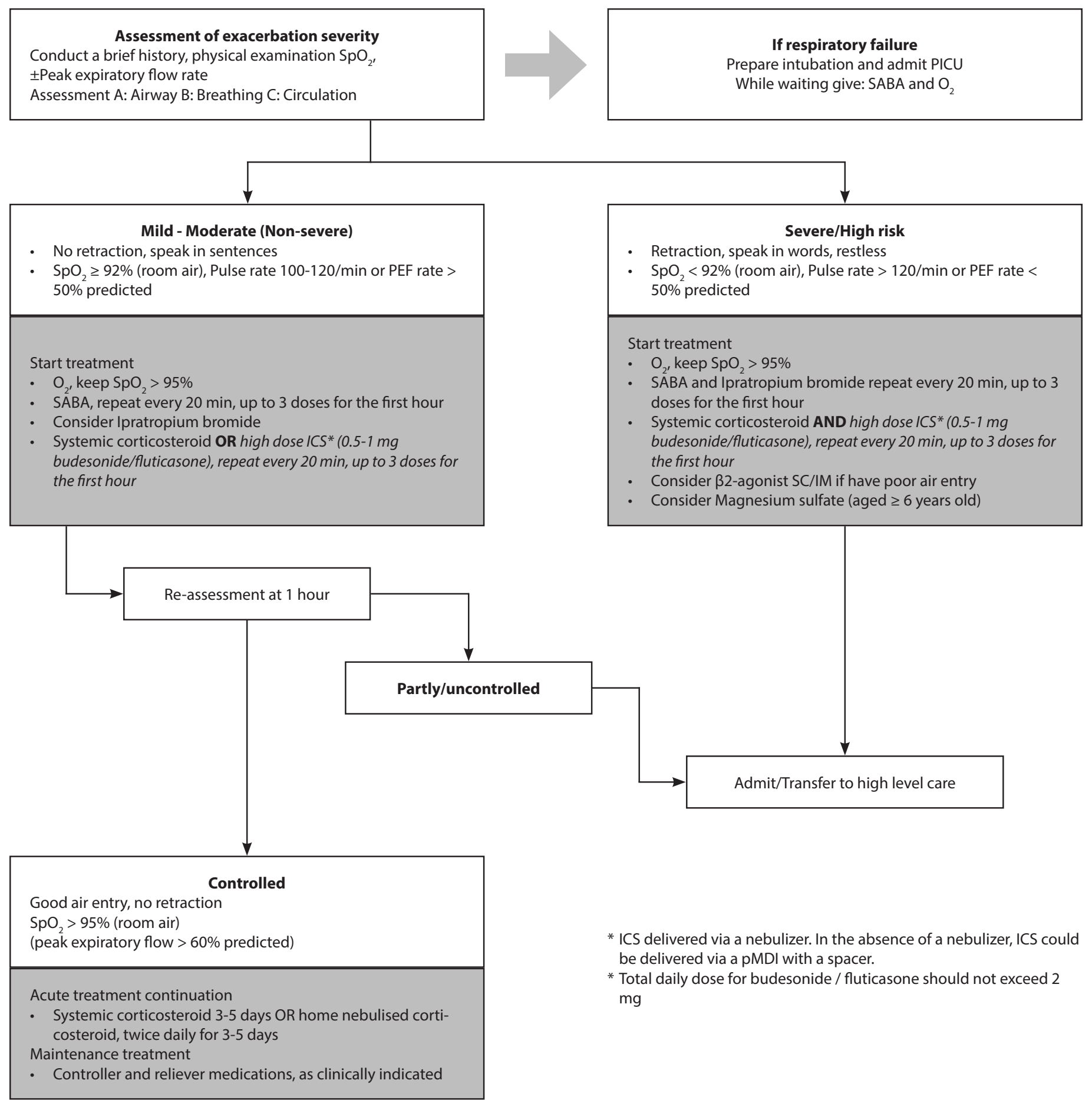

Adapted from Thai Pediatric Asthma Guideline 2015-2016

Figure 1. Management of pediatric asthma exacerbation in hospital 


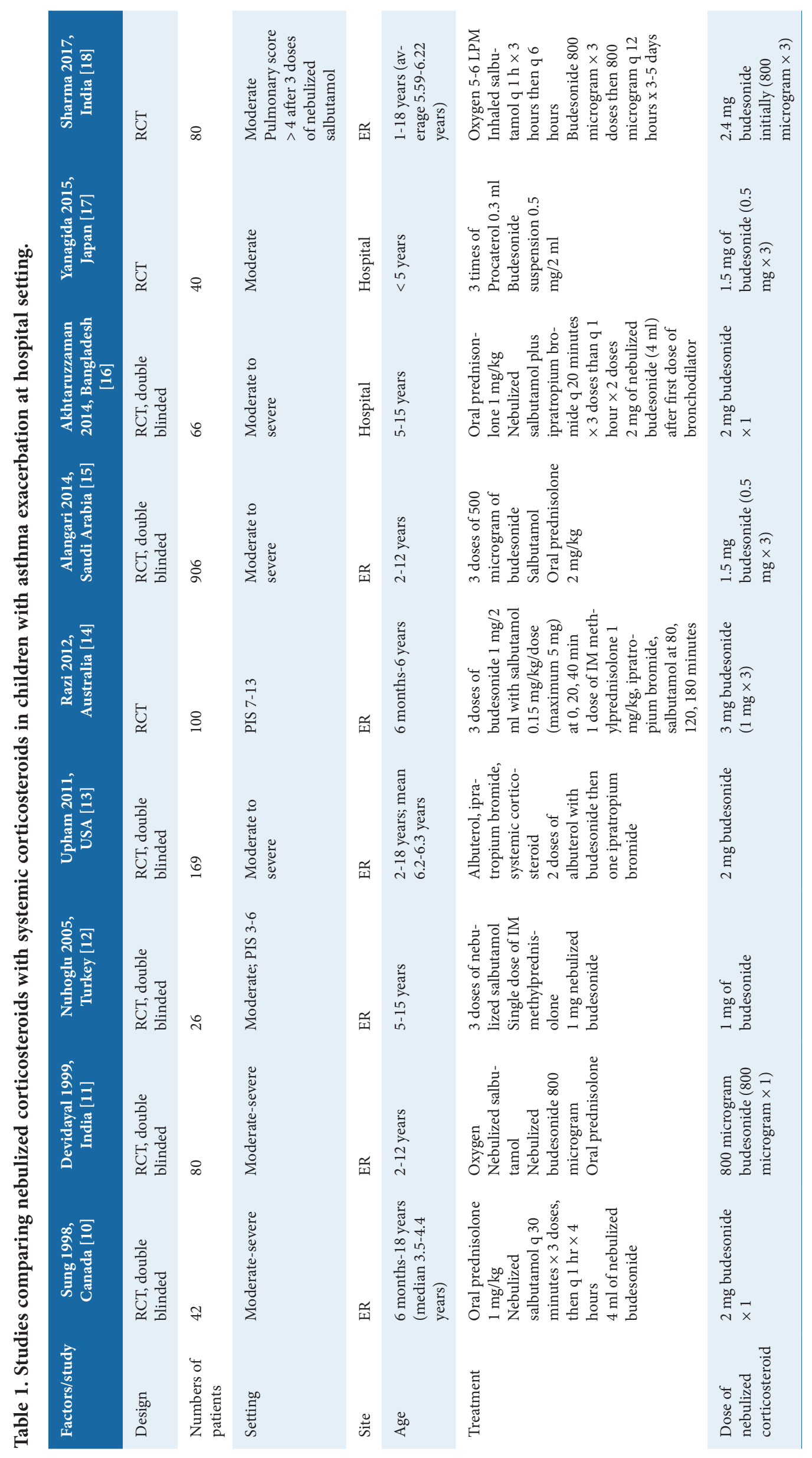




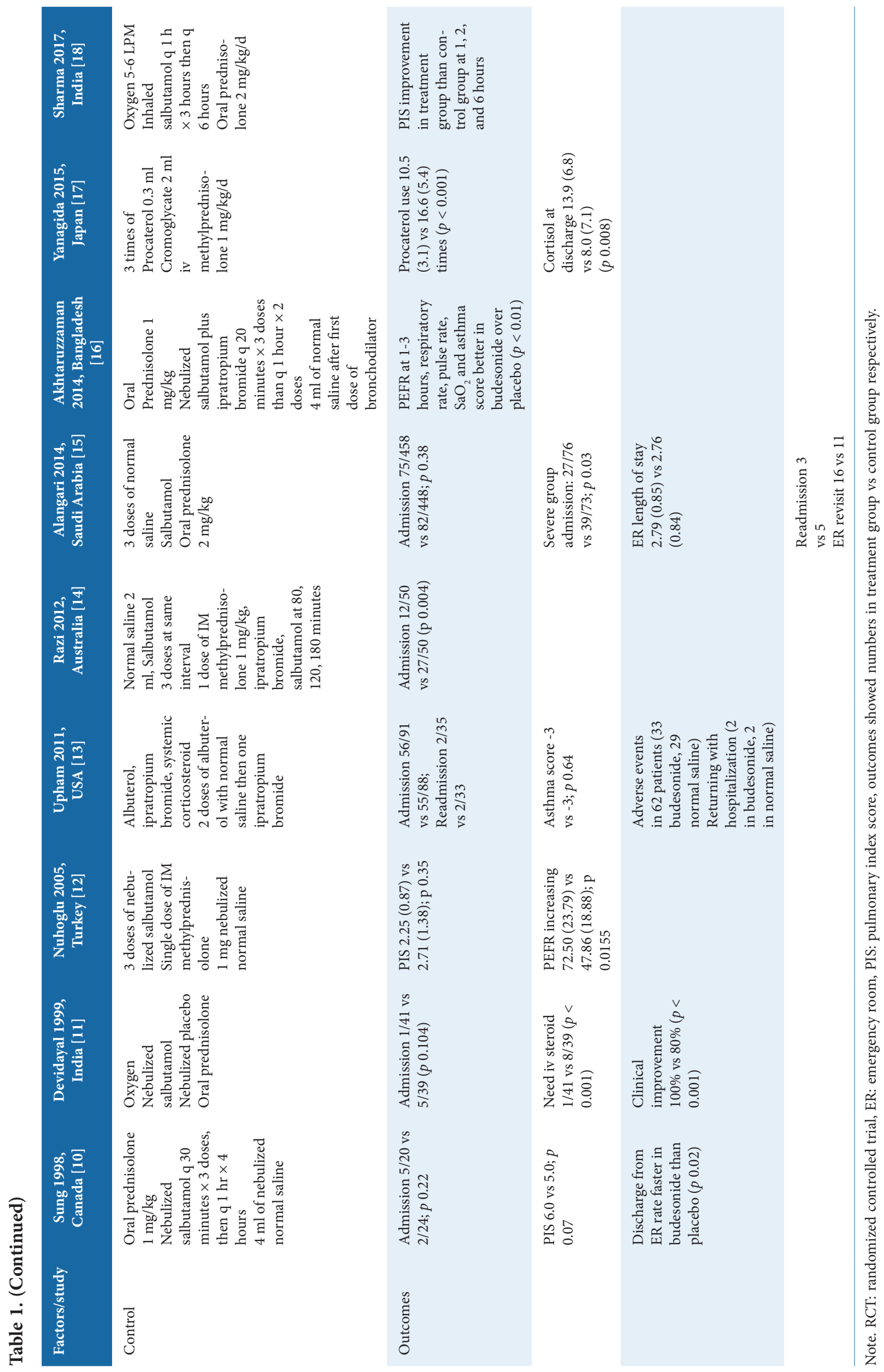


Table 2. Studies comparing nebulized corticosteroids with placebo in children with asthma exacerbation at hospital setting.

\begin{tabular}{|c|c|c|c|c|}
\hline Factors/study & Milani 2004, Brazil [19] & Sekerel 2005, Turkey [20] & Estrada 2005, Mexico ${ }^{\star \star}[21]$ & Chen 2013, China [20] \\
\hline Design & RCT, double blinded & RCT, double blinded & RCT, double blinded & RCT, double blinded \\
\hline Numbers of patients & 49 & 67 & 150 & 118 \\
\hline Setting & Moderate & Mild to moderate & Moderate & Moderate to severe \\
\hline Site & Clinic & ER & ER & ER \\
\hline Age & $2-7$ years & $6-15$ years & Mean $9.8-10$ years & Mean 7.9-8.2 years \\
\hline Treatment & $\begin{array}{l}3 \mathrm{ml} \text { of salbutamol } \\
4 \mathrm{ml} \text { of budesonide }(2 \mathrm{mg})\end{array}$ & $\begin{array}{l}3 \text { doses of nebulized } \\
\text { budesonide }(1 \mathrm{mg} / \mathrm{dose}) \text { at ER } \\
\text { Nebulized budesonide twice/ } \\
\text { day } \times 4 \text { days at home }\end{array}$ & $\begin{array}{l}3 \text { doses of salbutamol } 30 \\
\text { microgram/kg plus fluticasone } \\
500 \text { microgram/dose q } 15 \\
\text { minutes }\end{array}$ & $\begin{array}{l}4 \mathrm{ml} \text { of mixture of salbu- } \\
\text { tamol, ipratropium and } 0.05 \% \\
\text { budesonide } 2 \mathrm{ml} \mathrm{q} 20 \text { minutes } \\
\times 3 \text { doses }\end{array}$ \\
\hline $\begin{array}{l}\text { Dose of nebulized } \\
\text { corticosteroid }\end{array}$ & 2 mg budesonide & $\begin{array}{l}3 \mathrm{mg} \text { at ER, total of } 11 \mathrm{mg} \text { of } \\
\text { budesonide }\end{array}$ & $1.5 \mathrm{mg}$ of fluticasone & $3 \mathrm{mg}$ of budesonide \\
\hline Control & $\begin{array}{l}3 \mathrm{ml} \text { of salbutamol } \\
4 \mathrm{ml} \text { of normal saline }\end{array}$ & $\begin{array}{l}\text { Same regimen but use normal } \\
\text { saline }\end{array}$ & $\begin{array}{l}3 \text { doses of salbutamol } 30 \\
\text { microgram/kg q } 15 \text { minutes }\end{array}$ & $\begin{array}{l}4 \mathrm{ml} \text { of mixture of salbutamol, } \\
\text { ipratropium and normal saline } \\
2 \mathrm{ml} \text { q } 20 \text { minutes } \times 3 \text { doses }\end{array}$ \\
\hline \multirow[t]{3}{*}{ Outcomes } & $\begin{array}{l}\text { Admission } 0 / 17 \text { vs } 1 / 15 \\
(p 0.469)\end{array}$ & $\begin{array}{l}\text { Systemic corticosteroid need } \\
2 / 33 \text { vs } 7 / 34(p 0.07)\end{array}$ & $\begin{array}{l}\text { Treatment group had better } \\
\text { clinical score at } 2 \text { hours } \\
(p<0.05)\end{array}$ & $\begin{array}{l}\text { Admission } 3 / 59 \text { vs } 10 / 54 \\
(p 0.037)\end{array}$ \\
\hline & \multicolumn{3}{|l|}{$\begin{array}{l}\text { Clinical score at } 1-2 \text { hours } 6.2 \\
(2.2) \text { vs } 5.64(2.4)\end{array}$} & $\begin{array}{l}\text { Systemic corticosteroid need } \\
10 / 59 \text { vs } 25 / 54(p 0.011)\end{array}$ \\
\hline & & & & $\begin{array}{l}\text { Complete remission at } 2 \text { hours } \\
50 / 59 \text { vs } 25 / 54(p 0.004)\end{array}$ \\
\hline
\end{tabular}

Note. RCT: randomized controlled trial, * another group received inhaled placebo with oral prednisolone $1 \mathrm{mg} / \mathrm{kg}$, ${ }^{\star *}$ another group received 3 doses of salbutamol plus 2 doses of fluticasone 500 microgram/dose, outcomes showed numbers in treatment group vs control group respectively.

\section{Nebulization Regimen}

- Nebulized corticosteroid should be administered within the first hour of presentation to the hospital and could be administered concurrently in a mixture with or sequentially after a nebulized dose of short-acting bronchodilator.

- Each dose of nebulized solution of corticosteroid and short-acting bronchodilator, delivered in a mixture or separately, could be repeated every 20 minutes, up to three doses for the first hour.

- As part of an acute treatment, two nebulized doses are recommended within the first hour, any subsequent dose is determined by clinical outcome.

- The recommended nebulization dose for corticosteroid is 0.5-1 mg for budesonide and 0.5-1 mg for fluticasone per dose with a total daily dose of $2 \mathrm{mg}$ in acute exacerbation of asthma in children.

- The volume of nebulized agents should be between 2.5 and $4 \mathrm{ml}$ and can be nebulized within 15 minutes.

A meta-analysis found that using inhaled corticosteroid within one hour reduced hospitalizations by $56 \%$ even without systemic corticosteroid treatment. ${ }^{23}$ Most published studies use nebulized corticosteroid in 3 doses regimen, ${ }^{14,15,17,18,22}$ with a total dose of 2-3 mg of budesonide. ${ }^{10,13,14,16,18-20}$

\section{Nebulized vs Systemic Corticosteroid}

- In mild and moderate asthma exacerbation, nebulized corticosteroid may be more appropriate than systemic corticosteroid at the healthcare facility [e.g. Emergency Room].
- In severe asthma exacerbation, nebulized corticosteroid could be a fast-acting add-on to systemic corticosteroid in the first hour of acute treatment.

When compared with systemic corticosteroids, nebulized corticosteroid is equivalent to systemic corticosteroids in terms of hospital admission rate but is more superior in clinical outcomes measured by clinical scores, pulmonary function test, ER length of stay, or intravenous steroid need [Table 1]. In terms of safety profile, suppression of pituitary adrenal axis may be more in systemic corticosteroids than nebulized budesonide. ${ }^{17}$ These safety findings are also found in several studies. $^{22,24-26}$ In addition, nebulized corticosteroids have faster action than systemic corticosteroids [1-2 hours versus 4 hours]. They improve pulmonary score faster than systemic corticosteroid. ${ }^{18}$ They also have more local effects on airways to reduce airway swelling and airway spasms. Both effects are from local pharmacology of nebulized corticosteroids including reduction of sputum eosinophils and reduction of adenosine 5'-monophosphate from topical nongenomic vasoconstriction. ${ }^{27-30}$

For economic concern, the absolute cost of high-dose nebulized corticosteroid is higher than oral prednisolone in acute asthma exacerbation, the total cost - including savings from shortened the hospital stay - of nebulized corticosteroid may be lower than oral prednisolone. The study showed that hospital length of stay was shorter by 36 hours and the cost of treatment with budesonide was lower by 130 USD compared with placebo. ${ }^{14}$ 
Table 3. Pharmacological properties of budesonide and fluticasone

\begin{tabular}{lll}
\multicolumn{1}{c}{ ICS } & \multicolumn{1}{c}{ Budesonide } & Fluticasone \\
\hline Mean Absorption Time & 1 hour & 7 hours \\
\hline Tmax & 15.5 mins & 50.8 mins \\
Half life & 2.8 hours and low systemic potency & 14.4 hours and high systemic potency \\
\hline Water solubility $(\mu \mathrm{g} / \mathrm{ml})$ & 16 & $<0.1$ \\
\hline Dissolution time & 6 mins & $>8$ hours \\
\hline Residence time in airway/lung tissue & Similar or longer & Shorter \\
\hline Volume distribution & Low $(183 \mathrm{~L})$ & High $(318 \mathrm{~L})$ \\
\hline Pneumonia risk & Low & High \\
\hline
\end{tabular}

Table adapted from reference no. 31, 32

Note. ICS: Inhale Corticosteroid

\section{Post-Nebulization Monitoring}

- The clinical status of the patient should be evaluated at the end of each nebulized corticosteroid dose to determine whether any subsequent doses are needed.

- If three nebulized doses are required, the need for more intensive treatment and monitoring in the hospital is recommended.

- If the clinical status of the patient is improved at the end of the first hour of initiating nebulization, the patient should continue home nebulized corticosteroid for 3-5 days $^{18}$ if available or start systemic corticosteroid at home for 3-5 days.

- If the clinical status of the patient is not improved at the end of the first hour of initiating nebulization, the patient should be hospitalized, and be initiated or maintained on systemic corticosteroid as part of the inpatient treatment.

For those with clinical responses with nebulized corticosteroid, defined by improvement of clinical score such as asthma index or pulmonary index score, short-term corticosteroids are needed. If available, home nebulized budesonide is justified with a dose of $1 \mathrm{mg}$ twice a day for 3-5 days. An alternative treatment is oral prednisolone $0.5-1 \mathrm{mg} / \mathrm{kg} /$ day for 3-5 days. Note that those with clinical responses may have a risk of ER revisit and hospitalization rate of $4.18 \%$ [16/383] and $0.78 \%[3 / 383]$, respectively. ${ }^{15}$

\section{Choice of Corticosteroid}

- Nebulized budesonide is the preferred corticosteroid.

- Nebulized fluticasone is an alternative if budesonide is not available.

First, pharmacological properties of budesonide are better than fluticasone [Table 3]. Budesonide has faster absorption time [ $1 \mathrm{hr}$ vs $7 \mathrm{hr}$ ], more water solubility [16 vs $0.1 \mathrm{mi}-$ crogram/ml], and longer deposit in airways or lung tissues than fluticasone. ${ }^{31}$ Second, budesonide has lower pneumonia risk which is relatively constant across all doses, while fluticasone increases risks of pneumonia as a dose-dependent fashion. ${ }^{32}$ Finally, budesonide has lower systemic side effects than fluticasone. ${ }^{31}$ These findings may indicate that nebulized budesonide has faster clinical improvement and fewer side effects than nebulized fluticasone.

\section{Home Nebulization}

- Home nebulization may be considered only for a short period as a continuation of the acute treatment in a healthcare facility after demonstrable improvement in the clinical status of the patient who first presented with acute asthmatic exacerbation

- Home nebulized corticosteroid should be administered twice a day as maintenance for 3-5 days after clinical improvement following acute treatment of acute asthmatic exacerbation

- The use and care of a nebulizer should be based on the recommendations from the American Association for Respiratory Care.

There is no randomized controlled trial comparing nebulized corticosteroids and inhaled corticosteroids to treat home asthma exacerbations in children. Currently, there are some evidence of inhaled corticosteroids at home for treat and prevent asthma exacerbations as follows:

A meta-analysis study compared an increasing and stable dose of inhaled corticosteroids to treat asthma exacerbations at home in patients with mild to moderate asthma. ${ }^{33}$ The study included three studies with 422 children and five studies with 1,247 adults. The primary outcome of this study was treatment failure identified by a need of rescue systemic corticosteroids. A sub-group analysis in children showed that increasing dose of inhaled corticosteroids at home was not better than stable dose of inhaled corticosteroids [odds ratio of $0.93 ; 95 \%$ confidence interval of $0.61,1.41]$ for the primary outcome.

Another study in children compared a quintupled dose of fluticasone [220 microgram/inhalation; twice a day] for seven days versus low-dose fluticasone [44 microgram/inhalation; twice a day]. This study was a randomized, double-blind study conducted in 17 sites in the US with 254 mild to moderate children with history of one exacerbation in the past years. The average age of all patients was 8.0 [SD 1.9] years. ${ }^{34}$ The study found that severe asthma exacerbations/year 
were comparable between both groups [0.48 vs 0.37 in quintupled dose and low-dose; $p$ value 0.30$]$. Other outcomes were also not statistically different between both groups such as the time to the first exacerbation or the rate of treatment failure. A study conducted in Turkey using a 4-, 8-, and 8-day of inhaled corticosteroid plus azithromycin at home to treat asthma exacerbation also found good response rate at $84 \%, 83 \%$, and $94 \%$ of the three regimens. ${ }^{35}$ The inhaled corticosteroids in this study were budesonide and fluticasone.

The role of inhaled corticosteroid at home in children with mild to moderate asthma to treat asthma exacerbations are still controversial. The home regimen, types, or duration of inhaled corticosteroid use are still limited. For nebulized corticosteroid, there is no clinical data to show efficacy on treatment and prevention of asthma exacerbation at home. One study from Turkey evaluated nebulized budesonide versus placebo at home after the ER visit. ${ }^{20}$ The $1 \mathrm{mg}$ of budesonide or placebo was given twice a day for four days. The FEV1 improvement in both groups for both short term [at ER] and long term [day sixth] were not statistical different. The home nebulized budesonide group had a trend of fewer patients who required systemic corticosteroid than placebo group [2/33 vs $7 / 34 ; p$ value 0.073$]$. No major side effects of nebulized budesonide were reported in a 72 -hour study. ${ }^{19}$ Two out of 17 patients [11.76\%] had coughing, while one out of 15 patients [6.67\%] in placebo group did. Nebulized corticosteroid treatment at home needs more attention on care, use, and side effects.

\section{Conclusions}

Nebulized corticosteroid may offer an effective therapeutic option for the management of acute exacerbation of asthma in all severities. It may be used within the first hour of presentation of acute treatment. Nebulized budesonide is the preferred corticosteroid. Home nebulization if available may be used for a short period as a continuation of the acute treatment in a healthcare facility only after demonstrable improvement in the clinical status of the patient who first presented with acute asthmatic exacerbation.

\section{Acknowledgement}

The development of this manuscript was supported by an unrestricted educational grant from AstraZeneca (Thailand) Ltd. All authors have read and approved the final manuscript and take full responsibility for the accuracy of its content.

\section{References}

1 Trakultivakorn M, Sangsupawanich S, Vichyanond P. Time trends of the prevalence of asthma, rhinitis and eczema in Thai children-ISAAC (International Study of Asthma and Allergies in Childhood) Phase Three. J Asthma. 2007;44:609-11.

2. Teeratakulpisarn J, Pairojkul S, Heng S. Survey of the prevalence of asthma, allergic rhinitis and eczema in school-children in Khon Kaen, northeastern Thailand using the ISAAC questionnaire: phase III. Asian Pac J Allergy Immunol. 2004;22:175-81

3. Wanlapakorn N, Sritippayawan S, Deerojanawong J. Prevalence of asthma, level of control and factors associated with asthma control in Thai elementary school students in Bangkok. Asian Pac J Allergy Immunol. 2014;32:287-92.
4. Boonsawat W, Thompson PJ, Zaeoui U, Samosorn C, Acar G, Faruqi R, et al. Survey of asthma management in Thailand - the asthma insight and management study. Asian Pac J Allergy Immunol. 2015;33:14-20.

5. Trakultivakorn M. Economic burden of asthma in Thailand. Asian Pac J Allergy Immunol. 2012;30:1.

6. Puranitee P, Kamchaisatian W, Manuyakorn W, Vilaiyuk S, Laecha O, Pattanaprateep $\mathrm{O}$, et al. Direct medical cost of Thai pediatric asthma management: a pilot study. Asian Pac J Allergy Immunol. 2015;33:296-300.

7. The Global Initiative for Asthma (GINA) [Internet]. Bethesda: Global Initiative for Asthma; c2018. Global Strategy for Asthma Management and Prevention (2018 Update) [cited 2018 Jul 23]; [about 1 screen]. Available from: https://ginasthma.org/2018-gina-report-global-strategy-for-asthma -management and-prevention/.

8. Olveira C, Muñoz A, Domenech A. Nebulized therapy. SEPAR year. Arch Bronconeumol. 2014;50:535-45.

9. Pediatric Society of Thailand [Internet]. Bangkok: The Royal College of Pediatricians of Thailand \& Pediatric Society of Thailand; c2008-2009. Thai Pediatric Asthma guideline 2015-2016 [cited 2018 Jul 23]; [about 1 screen]. Available from: http://www.thaipediatrics.org/Media/media-2016 1130084703.pdf

10. Sung L, Osmond MH, Klassen TP. Randomized, controlled trial of inhaled budesonide as an adjunct to oral prednisone in acute asthma. Acad Emerg Med. 1998;5:209-13.

11. Devidayal, Singhi S, Kumar L, Jayshree M. Efficacy of nebulized budesonide compared to oral prednisolone in acute bronchial asthma. Acta Paediatric. 1999;88:835-40.

12. Nuhoglu Y, Atas E, Nuhoglu C, Iscan M, Ozcay S. Acute effect of nebulized budesonide in asthmatic children. J Investig Allergol Clin Immunol. 2005; 15:197-200.

13. Upham BD, Mollen CJ, Scarfone RJ, Seiden J, Chew A, Zorc JJ. Nebulized budesonide added to standard pediatric emergency department treatment of acute asthma: a randomized, double-blind trial. Acad Emerg Med. 2011;18:665-73.

14. Razi CH, Cörüt N, Andıran N. Budesonide for emergency treatment of acute wheezing in children. Pediatr Pulmonol. 2017;52:720-8.

15. Alangari AA, Malhis N, Mubasher M, Al-Ghamedi N, Al-Tannir M, Riaz $\mathrm{M}$, et al. Budesonide nebulization added to systemic prednisolone in the treatment of acute asthma in children: a double-blind, randomized, controlled trial. Chest. 2014;145:772-8.

16. Akhtaruzzaman M, Ahmed SU, Hoque MA, Choudhury AM, Hossain MA, Islam MN, et al. Effects of nebulized budesonide as an adjunct to standard treatment of asthma exacerbations: a randomized, double-blind, placebo-controlled trial. Mymensingh Med J. 2014;23:418-25.

17. Yanagida N, Tomikawa M, Shukuya A, Iguchi M, Ebisawa M. Budesonide inhalation suspension versus methylprednisolone for treatment of moderate bronchial asthma attacks. World Allergy Organ J. 2015;8:14.

18. Sharma S, Harish R, Dutt N, Digra KK. To evaluate the efficacy of nebulized budesonide compared to oral prednisolone in the management of moderate exacerbation of acute asthma. Int J Contemp Pediatr. 2017:4:1278-83.

19. Milani GK, Rosario Filho NA, Riedi CA, Figueiredo BC. Nebulized budesonide to treat acute asthma in children. J Pediatr (Rio J). 2004;80. 106-12. Portuguese.

20. Sekerel BE, Sackesen C, Tuncer A, Adalioglu G. The effect of nebulized budesonide treatment in children with mild to moderate exacerbations of asthma. Acta Paediatrica. 2005;94:1372-7.

21. Estrada-Reyes E, Del Rio-Navarro BE, Rosas-Vargas MA, Nava-Ocampo AA. Co-administration of salbutamol and fluticasone for emergency treatment of children with moderate acute asthma. Pediatr Allergy Immunol. 2005; 16:609-14.

22. Chen AH, Zeng GQ, Chen RC, Zhan JY, Sun LH, Huang SK, et al. Effects of nebulized high-dose budesonide on moderate-to-severe acute exacerbation of asthma in children: a randomized, double-blind, placebo-controlled study. Respirology. 2013;18:47-52.

23. Edmonds ML, Milan SJ, Camargo CA Jr, Pollack CV, Rowe BH. Early use of inhaled corticosteroids in the emergency department treatment of acute asthma. Cochrane Database Syst Rev. 2012;12:CD002308.

24. Saito M, Kikuchi Y, Kawarai Lefor A, Hoshina M. High dose nebulized budesonide is effective for mild asthma exacerbations in children under 3 years of age. Eur Ann Allergy Clin Immunol. 2017;49:22-7.

25. Irani AM, Cruz-Rivera M, Fitzpatrick S, Hoag J, Smith JA. Effects of budesonide inhalation suspension on hypothalamic-pituitary-adrenal-axis function in infants and young children with persistent asthma. Ann Allergy Asthma Immunol. 2002;88:306-12. 
APJAI

26. Wilson AM, McFarlane LC, Lipworth BJ. Systemic bioactivity profiles of oral prednisolone and nebulized budesonide in adult asthmatics. Chest. 1998;114:1022-7.

27. Belda J, Margarit G, Martínez C, Bellido-Casado J, Casan P, Torrejón M, et al. Anti-inflammatory effects of high-dose inhaled fluticasone versus oral prednisone in asthma exacerbations. Eur Respir J. 2007;30:1143-9.

28. Ketchell RI, Jensen MW, Lumley P, Wright AM, Allenby MI, O'Connor BJ. Rapid effect of inhaled fluticasone propionate on airway responsiveness to adenosine 59 -monophosphate in mild asthma. J Allergy Clin Immunol. 2002;110:603-6.

29. Horvath G, Wanner A. Inhaled corticosteroids: effects on the airway vasculature in bronchial asthma. Eur Respir J. 2006;27:172 - 87.

30. Alangari AA. Genomic and non-genomic actions of glucocorticoids in asthma. Ann Thorac Med. 2010;5:133-9.
31. Edsbäcker S, Wollmer P, Selroos O, Borgström L, Olsson B, Ingelf J. Do airway clearance mechanisms influence the local and systemic effects of inhaled corticosteroids? Pulm Pharmacol Ther. 2008;21:247-58.

32. Janson C, Stratelis G, Miller-Larsson A, Harrison TW, Larsson K. Scientific rationale for the possible inhaled corticosteroid intraclass difference in the risk of pneumonia in COPD. Int J Chron Obstruct Pulmon Dis. 2017;12:3055-64.

33. Kew KM, Quinn M, Quon BS, Ducharme FM. Increased versus stable doses of inhaled corticosteroids for exacerbations of chronic asthma in adults and children. Cochrane Database Syst Rev. 2016;6:CD007524.

34. Jackson DJ, Bacharier LB, Mauger DT, Boehmer S, Beigelman A, Chmiel JF, et al. Quintupling Inhaled Glucocorticoids to Prevent Childhood Asthma Exacerbations. N Engl J Med. 2018;378:891-901.

35. Volovitz B, Bilavsky E, Nussinovitch M. Effectiveness of high repeated doses of inhaled budesonide or fluticasone in controlling acute asthma exacerbations in young children. J Asthma. 2008;45:561-7. 